\title{
Glycogen synthase kinase $3 \beta$ inhibitors protect hippocampal neurons from radiation-induced apoptosis by regulating MDM2-p53 pathway
}

\author{
DK Thotala ${ }^{1}$, DE Hallahan ${ }^{1,2,3}$ and EM Yazlovitskaya ${ }^{\star, 4,5}$
}

Exposure of the brain to ionizing radiation can cause neurocognitive deficiencies. The pathophysiology of these neurological changes is complex and includes radiation-induced apoptosis in the subgranular zone of the hippocampus. We have recently found that inhibition of glycogen synthase kinase $3 \beta$ (GSK-3 $\beta$ ) resulted in significant protection from radiation-induced apoptosis in hippocampal neurons. The molecular mechanisms of this cytoprotection include abrogation of radiation-induced accumulation of p53. Here we show that pretreatment of irradiated HT-22 hippocampal-derived neurons with small molecule inhibitors of GSK-3 $\beta$ SB216763 or SB415286, or with GSK-3 $\beta$-specific shRNA resulted in accumulation of the p53-specific E3 ubiquitin ligase MDM2. Knockdown of MDM2 using specific shRNA or chemical inhibition of MDM2-p53 interaction prevented the protective changes triggered by GSK-3 $\beta$ inhibition in irradiated HT-22 neurons and restored radiation cytotoxicity. We found that this could be due to regulation of apoptosis by subcellular localization and interaction of GSK-3 $\beta$, p53 and MDM2. These data suggest that the mechanisms of radioprotection by GSK-3 $\beta$ inhibitors in hippocampal neurons involve regulation of MDM2dependent p53 accumulation and interactions between GSK-3 $\beta$, MDM2 and p53.

Cell Death and Differentiation (2012) 19, 387-396; doi:10.1038/cdd.2011.94; published online 8 July 2011

The hippocampus is a critical neurological center for cognitive abilities, ${ }^{1}$ and its damage from radiation therapy leads to defects in learning, memory, spatial navigation, visual motor processing, quantitative skills and attention. ${ }^{2}$ Independent of dose and manner of exposure (brain only or whole body), cells of the dentate subgranular zone (SGZ) are extremely sensitive to irradiation, undergoing apoptosis after doses ranging from 0.4 to $18 \mathrm{~Gy}^{2-7}$ There is a number of studies using animal models that show close relations between neurogenesis and cognitive function after irradiation. ${ }^{5,8-11}$ Our recent study demonstrated that inhibition of glycogen synthase kinase $3 \beta$ (GSK-3 $\beta$ ) by lithium or small molecule inhibitors resulted in significant protection from radiationinduced apoptosis in hippocampal neurons. ${ }^{5,11}$ As a result, we observed significant improvement in cognitive performance of mice treated with GSK-3 $\beta$ inhibitors before cranial irradiation. These findings suggest potential novel mechanism of radioprotection of hippocampal neurons involving inhibition of GSK-3 $\beta$.

GSK-3 is a serine/threonine kinase that was initially identified as an enzyme that regulates glycogen synthesis. ${ }^{12}$ GSK-3 $\beta$, one of two GSK-3 isoforms, is widely expressed and participates in multiple cellular processes such as cell growth and differentiation, structure and functions and cell survival. ${ }^{13-17}$ Direct overexpression of wild-type GSK-3 $\beta$ is known to induce apoptosis in various cell types in culture, and specific inhibitors of GSK-3 $\beta$ are able to ameliorate this apoptotic process. ${ }^{5,14,15,18}$ GSK-3 $\beta$ is subject to multiple regulatory mechanisms including inhibiting $\left(\mathrm{Ser}^{9}\right)$ and activating $\left(\mathrm{Tyr}^{216}\right)$ phosphorylation, protein complex formation and intracellular localization. ${ }^{16,17,19,20}$ Subcellular localization of GSK-3 $\beta$ determines its access to substrates. Although GSK-3 $\beta$ is predominantly localized in cytosol, nuclear and mitochondrial fractions of GSK-3 $\beta$ are characterized by much higher activity. ${ }^{21}$ Nuclear localization of GSK-3 $\beta$ facilitates interaction with its nuclear substrates and leads to regulation of specific cellular function. For example, GSK-3 $\beta$-dependent phosphorylation and degradation of $\beta$-catenin also activates pro-apoptotic response. ${ }^{22}$

The tumor suppressor transcription factor $\mathrm{p} 53$ has been implicated in the pro-apoptotic actions of GSK-3 $\beta$ in several studies. ${ }^{23,24}$ Following DNA damage, the normally short-lived p53 protein is stabilized and modified by a complex array of post-translational modifications, such as phosphorylation, acetylation, methylation, ubiquitination, sumoylation, glycosylation and neddylation, and a large number of proteins interact with p53 to regulate its actions. ${ }^{25,26}$ One of these regulatory proteins is GSK-3 $\beta$, which forms a complex with nuclear p53 to promote p53-induced apoptosis. ${ }^{23,27,28}$ GSK- $3 \beta$ binds directly to $p 53$, and the C-terminal region of

\footnotetext{
${ }^{1}$ Department of Radiation Oncology, Washington University School of Medicine, St. Louis, MO, USA; ${ }^{2}$ Siteman Cancer Center, Washington University School of Medicine, St. Louis, MO, USA; ${ }^{3}$ Mallinckrodt Institute of Radiology, Washington University School of Medicine, St. Louis, MO, USA; ${ }^{4}$ Department of Medcine, Division of Nephrology, Vanderbilt University School of Medicine, Nashville, TN 37232, USA and ${ }^{5}$ Vanderbilt-Ingram Cancer Center, Vanderbilt University School of Medicine, Nashville, TN 37232, USA

${ }^{*}$ Corresponding author: EM Yazlovitskaya, Department of Medcine, Division of Nephrology, Vanderbilt University School of Medicine, C3210 Medical Center North, 1161 21st Avenue South, Nashville, TN 37232, USA. Tel: 615322 6679; Fax: 615343 7156; E-mail: eugenia.yazlovitskaya @ vanderbilt.edu

Keywords: ionizing radiation; hippocampal neurons; GSK-3 $\beta$; MDM2; 553

Abbreviations: GSK-3 $\beta$, glycogen synthase kinase $3 \beta$; SGZ, subgranular zone; DAPI, 4',6-diamidino-2-phenylindole; FBS, fetal bovine serum; PBS, phosphatebuffered saline; GFP, green fluorescent protein

Received 15.9.10; revised 01.6.11; accepted 09.6.11; Edited by M Oren; published online 08.7.11
} 
p53 is necessary for this interaction. ${ }^{27}$ GSK-3 $\beta$ was shown to directly phosphorylate p53 at $\operatorname{Ser}^{33},{ }^{29}$ and to mediate p53 phosphorylation at $\operatorname{Ser}^{315}$ and $\operatorname{Ser}^{376}{ }^{30,31}$ GSK-3 $\beta$ promotes p53-mediated transcription of specific genes and regulates the intracellular localization of $p 53 .^{27,28,31}$ In addition to GSK$3 \beta$ regulating $\mathrm{p} 53, \mathrm{GSK}-3 \beta$ is also regulated by $\mathrm{p} 53$. The activity of GSK-3 $\beta$ is increased by a phosphorylationindependent mechanism of a direct binding of p53 to GSK$3 \beta .^{23}$ Nuclear localization of GSK-3 $\beta$ also could be regulated by binding of activated $p 53 .^{24}$

In addition to direct interaction, GSK-3 $\beta$ can regulate p53 levels through the phosphorylation of the p53-specific E3 ubiquitin ligase MDM2. ${ }^{32}$ Regulation of $p 53$ by MDM2 is multifaceted. In the classical model, N-terminal phosphorylation of p53 at $\operatorname{Ser}^{15}$ (mouse $\operatorname{Ser}^{18}$ ) and $\operatorname{Ser}^{20}$ (mouse Ser ${ }^{23}$ ) inhibits the interaction with MDM2 and thereby prevents MDM2-mediated ubiquitination and the resulting proteasomal degradation of $p 53 .{ }^{26}$ Stabilized p53 is subjected to a complex regulatory network to induce DNA binding and transcriptional activation of p53 target genes, in part through the recruitment of coactivators and corepressors. This determines the specific cellular response including survival, growth arrest, DNA repair or apoptosis. $^{26}$

We have previously shown that inhibition of GSK-3 $\beta$ protects hippocampal neurons from radiation-induced apoptosis. ${ }^{5,11}$ In the present study, we found that the mechanisms of this protection involved subcellular localization and interaction of GSK-3 $\beta$, p53 and MDM2. In HT-22 hippocampalderived neurons, GSK-3 $\beta$ inhibitors blocked radiation-induced accumulation of p53 by upregulating levels of MDM2 that subsequently resulted in decreased radiation-dependent apoptosis. Knockdown of MDM2 using specific shRNA or chemical inhibition of MDM2-p53 interaction prevented protective changes triggered by GSK-3 $\beta$ inhibition in irradiated HT-22 neurons and restored radiation cytotoxicity. These results suggest a pivotal role of MDM2-p53 axis in radioprotective effects of GSK- $3 \beta$ inhibitors.

\section{Results}

GSK-3 $\beta$ inhibition increases MDM2 and abrogates radiation-induced p53 accumulation. To analyze the effects of GSK-3 $\beta$ inhibitors on p53 and MDM2 accumulation, HT-22 cells were treated with $10 \mu \mathrm{M}$ SB216763 or $25 \mu \mathrm{M}$ SB415286 for $16 \mathrm{~h}$, irradiated with $3 \mathrm{~Gy}$, lysed at $6 \mathrm{~h}$ after irradiation and subjected to immunoblot analysis. Protein level of $\beta$-catenin was used to evaluate GSK-3 $\beta$ activity. ${ }^{5,11}$ Irradiation with 3 Gy increased phosphorylation of $\mathrm{p} 53$ at $\mathrm{Ser}^{18}$ and resulted in p53 accumulation, but did not significantly affect level of MDM2 (Figure 1). As expected, treatment with SB216763 and SB415286 elevated the accumulation/stabilization of $\beta$ catenin compared with their respective controls indicating GSK-3 $\beta$ inhibition. Interestingly, GSK-3 $\beta$ inhibitors significantly increased levels of MDM2, but did not affect p53 accumulation. In combination, GSK-3 $\beta$ inhibitors with radiation produced a sustained increase in the level of MDM2, whereas radiation-induced p53 accumulation was abrogated (Figure 1).

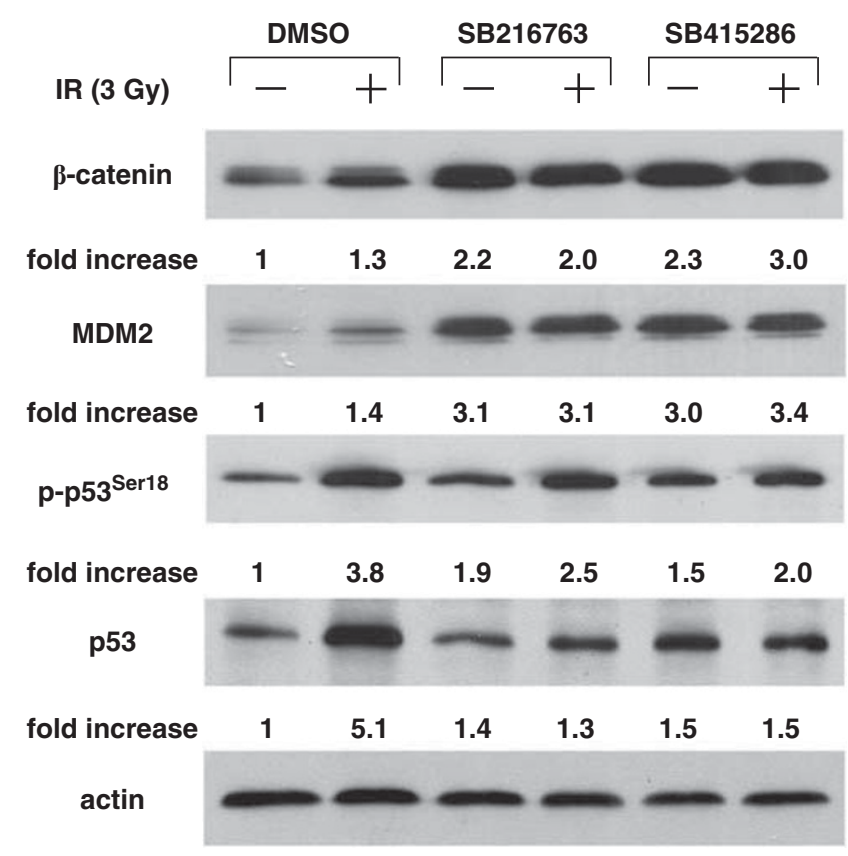

Figure 1 GSK-3 $\beta$ inhibition leads to increased level of MDM2 and abrogates radiation-induced p53 accumulation. HT-22 neurons were treated with $10 \mu \mathrm{M}$ SB216763 or $25 \mu \mathrm{M}$ SB415286 for $16 \mathrm{~h}$, irradiated with $3 \mathrm{~Gy}$ and harvested $6 \mathrm{~h}$ after radiation. Cellular proteins were immunoblotted using antibodies to phospho-p53 $\left(\mathrm{Ser}^{18}\right)$, p53, MDM2 and $\beta$-catenin to analyze levels of expression of these proteins. Actin was used to evaluate the protein loading in each lane. Relative protein levels were determined by densitometry and normalized to actin and to control (cells treated with DMSO)

MDM2 mediates the effect of GSK-3 $\beta$ inhibitors on radiation-induced accumulation of $\mathrm{p} 53$. As the stability of $\mathrm{p} 53$ is predominantly regulated by MDM2 and GSK-3 $\beta$ inhibitors prevent radiation-induced p53 accumulation, we studied the role of MDM2 in this process by knocking down MDM2 in HT-22 neurons using shRNA (Figure 2a). When transfected with non-silencing shRNA, HT-22 neurons treated with GSK-3 $\beta$ inhibitors demonstrated prevention of radiation-induced p53 accumulation (Figure 2a, lanes 1-6) similar to the response observed previously (Figure 1). In contrast, MDM2 knockdown by specific shRNA resulted in p53 accumulation, which was sustained under all conditions, including radiation, treatment with GSK-3 $\beta$ inhibitors and their combination (Figure 2a, lanes 7-12). To further study the role of MDM2 in the observed phenomenon, we knocked down GSK-3 $\beta$ using specific shRNA, and inhibited MDM2p53 interaction by either nutlin-3a or RITA, in irradiated HT-22 neurons. As expected, in HT-22 neurons transfected with non-silencing shRNA, radiation resulted in p53 accumulation (Figure 2b, lanes 1-2). Inhibition of MDM2p53 interaction either by $10 \mu \mathrm{M}$ nutlin-3a or $1 \mu \mathrm{M}$ RITA also led to accumulation of p53 in the presence of GSK-3 $\beta$ (Figure 2b, lanes 3-6). In contrast, after knockdown of GSK$3 \beta$, treatment of HT-22 neurons with radiation, inhibitors of MDM2-p53 interaction or combination of both did not result in the significant accumulation of p53 (Figure 2b, lanes 7-12). 
a
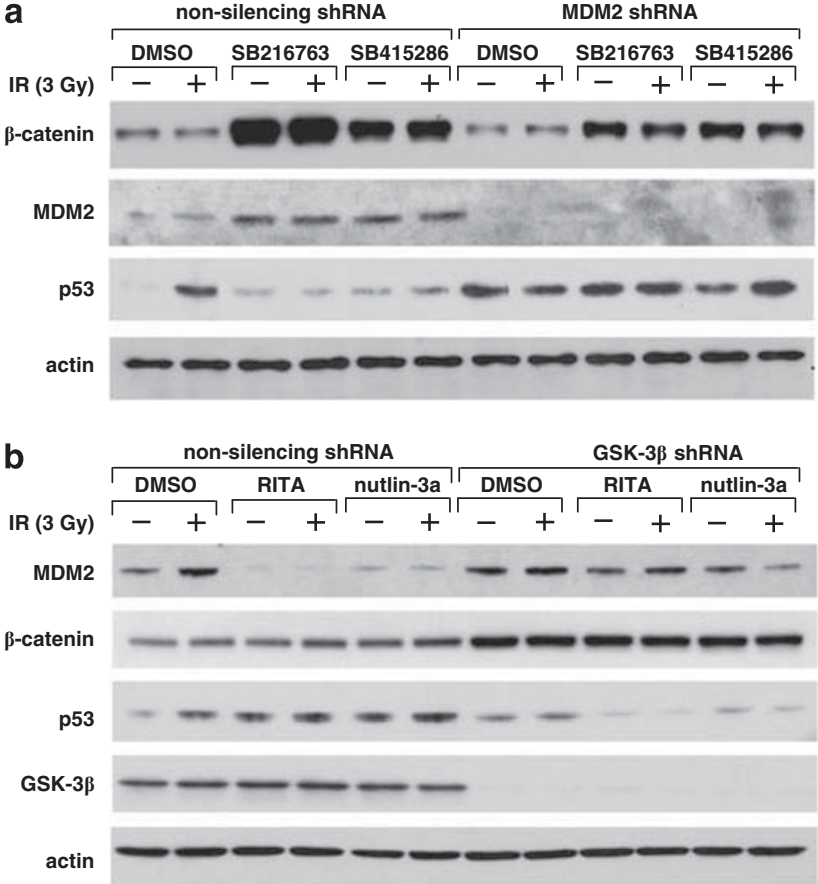

Figure 2 MDM2 mediates the effect of GSK-3 $\beta$ inhibition on radiation-induced accumulation of p53. (a) HT-22 neurons were transiently transfected with the nonsilencing or MDM2-specific shRNA co-expressing GFP in a bicystronic vector. The GFP-positive cells were sorted, treated with DMSO, $10 \mu \mathrm{M}$ of SB216763 or $25 \mu \mathrm{M}$ of SB415286 for $16 \mathrm{~h}$, irradiated with $3 \mathrm{~Gy}$ and harvested $6 \mathrm{~h}$ after radiation. Cellular proteins were immunoblotted using antibodies to MDM2, $\beta$-catenin and p53 to analyze levels of expression of these proteins. Actin was used to evaluate the protein loading in each lane. (b) HT-22 neurons were infected with viruses generated in HEK293T cells transfected with the non-silencing or GSK-3 $\beta$-specific shRNA. The cells selected with puromycin were treated with DMSO, $1 \mu \mathrm{M}$ of RITA or $10 \mu \mathrm{M}$ of nutlin-3a for $16 \mathrm{~h}$, irradiated with $3 \mathrm{~Gy}$ and harvested $6 \mathrm{~h}$ after radiation. Cellular proteins were immunoblotted using antibodies to MDM2, $\beta$-catenin, GSK$3 \beta$ and p53 to analyze levels of expression of these proteins. Actin was used to evaluate the protein loading in each lane

Effect of GSK-3 $\beta$ inhibitors and irradiation on subcellular localization and interaction of GSK-3 $\beta$, p53 and MDM2. Using immunofluorescence microscopy (Figure $3 \mathrm{a}$ ) and immunoblot analysis of subcellular protein fractions (Figure $3 \mathrm{~b}$ ), at $6 \mathrm{~h}$ after irradiation with $3 \mathrm{~Gy}$, we observed a significant increase in nuclear p53 suggesting that radiation leads to predominant accumulation of nuclear p53 (Figures 3a and b). No significant changes occurred for GSK-3 $\beta$ or MDM2 subcellular localization (Figures $3 a$ and $b$ ). Treatment with GSK-3 $\beta$ inhibitors alone or in combination with radiation significantly reduced nuclear localization of p53 and increased cytosolic fraction of MDM2 (Figures $3 a$ and $b$ ).

To study interactions between GSK-3 $\beta$, p53 and MDM2, we performed co-immunoprecipitation experiments. In untreated HT-22 cells, p53 and MDM2 were detected in GSK-3 $\beta$ immunoprecipitations in both nuclear and cytoplasmic fractions, suggesting complex formation between these proteins (Figure 4a). Radiation dramatically decreased binding of p53 to GSK-3 $\beta$ in the cytoplasm but enhanced binding in the nucleus. SB216763 and SB415286 alone or in combination with radiation significantly decreased binding between GSK-3 $\beta$ and p53 in both fractions, thereby preventing radiation-induced three-protein complex formation in the nucleus (Figure 4a). Similar effects were observed with protein levels of GSK-3 $\beta$ and p53 detected in immunoprecipitations of MDM2 (Figure 4b). Taking together, these results demonstrate that GSK-3 $\beta$ inhibition decreases complex formation between GSK-3 $\beta$, p53 and MDM2 suggesting that GSK-3 $\beta$ activity is essential for interactions between GSK-3 $\beta$, p53 and MDM2 in subcellular compartments.

MDM2 mediates the cytoprotective effect of GSK-3 $\beta$ inhibitors in irradiated HT-22 neurons. To determine whether MDM2 is essential for the cytoprotective effect of GSK-3 $\beta$ inhibitors on irradiated HT-22 neurons, we performed colony forming assay following transfection with non-silencing or MDM2-specific shRNA. In HT-22 neurons transfected with non-silencing shRNA, GSK-3 $\beta$ inhibitor SB415286 showed significantly increased survival following irradiation (Figure 5a), confirming previously published results. ${ }^{5,11}$ However, transfection with MDM2-specific shRNA abrogated this increase (Figure 5a). We next performed colony-forming assay on irradiated HT-22 neurons with knocked down GSK-3 $\beta$ using specific shRNA and inhibition of MDM2-p53 interaction by nutlin-3a. Knockdown of GSK-3 $\beta$ led to an increased survival of irradiated HT-22 neurons compared with non-silencing control (Figure 5b), confirming the effects of GSK-3 $\beta$ chemical inhibitors (Figure 5a). ${ }^{5,11}$ Inhibition of MDM2-p53 interaction with $10 \mu \mathrm{M}$ nutlin-3a abrogated this cytoprotective effect (Figure $5 b$ ), supporting the results obtained with MDM2-specific shRNA (Figure 5a).

The role of MDM2 on programmed cell death was studied by apoptosis assays (Figures 6 and 7). Cells were first analyzed for apoptosis by annexin $\mathrm{V} /$ propidium iodide staining (Figure 6). HT-22 neurons transfected with non-silencing shRNA and pretreated with GSK-3 $\beta$ inhibitor SB415286 demonstrated a radioprotective effect with a reduced number of apoptotic cells compared with DMSO-pretreated-irradiated controls (Figure 6a, bar 4 versus 2). This protection was completely abrogated in irradiated HT-22 neurons transfected with MDM2-specific shRNA and pretreated with SB415286 (Figure 6a, bar 8 versus 2). HT-22 neurons transfected with non-silencing shRNA and pretreated with inhibitor of MDM2p53 interaction nutlin-3a showed amount of apoptosis compared to DMSO-pretreated-irradiated cells (Figure 6b, bar 4 versus 2). As expected, GSK-3 $\beta$ knockdown by specific shRNA led to a radioprotective effect compared with nonsilencing irradiated control (Figure 6b, bar 6 versus 2). Similar to Figure $6 \mathrm{a}$, treatment with nutlin-3a abolished the radioprotection by GSK-3 $\beta$ knockdown (Figure $6 \mathrm{~b}$, bar 8 versus 6 ).

We next evaluated the nuclear morphology of dying cells using 4',6-diamidino-2-phenylindole (DAPI) staining (Figure 7), and the results were similar to the assessment of apoptosis by annexin V/propidium iodide staining (Figure 6). We observed the cytoprotective effect of GSK-3 $\beta$ inhibitor SB415286 from radiation-induced apoptosis in HT-22 neurons that were transfected with non-silencing shRNA (Figures $7 \mathrm{a}$ and $\mathrm{b}$ ). This protection was completely abrogated in $\mathrm{HT}-22$ neurons transfected with MDM2-specific shRNA and pretreated with SB415286 (Figures 7a and b). The treatment of HT-22 neurons with inhibitor of MDM2-p53 interaction 
a
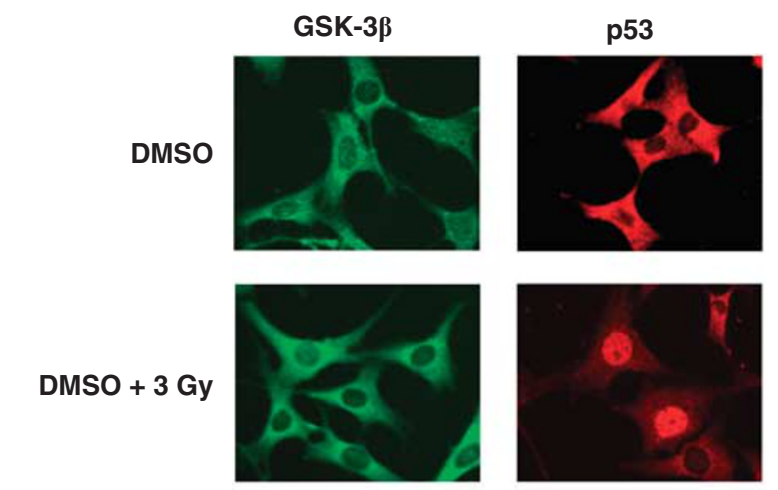

DMSO + 3 Gy
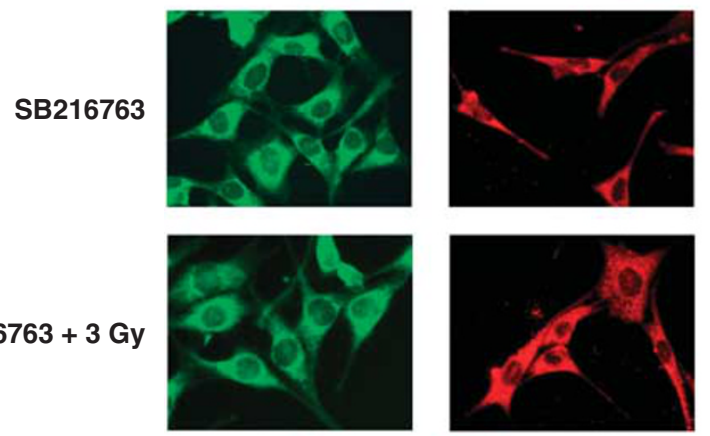

SB216763 + 3 Gy
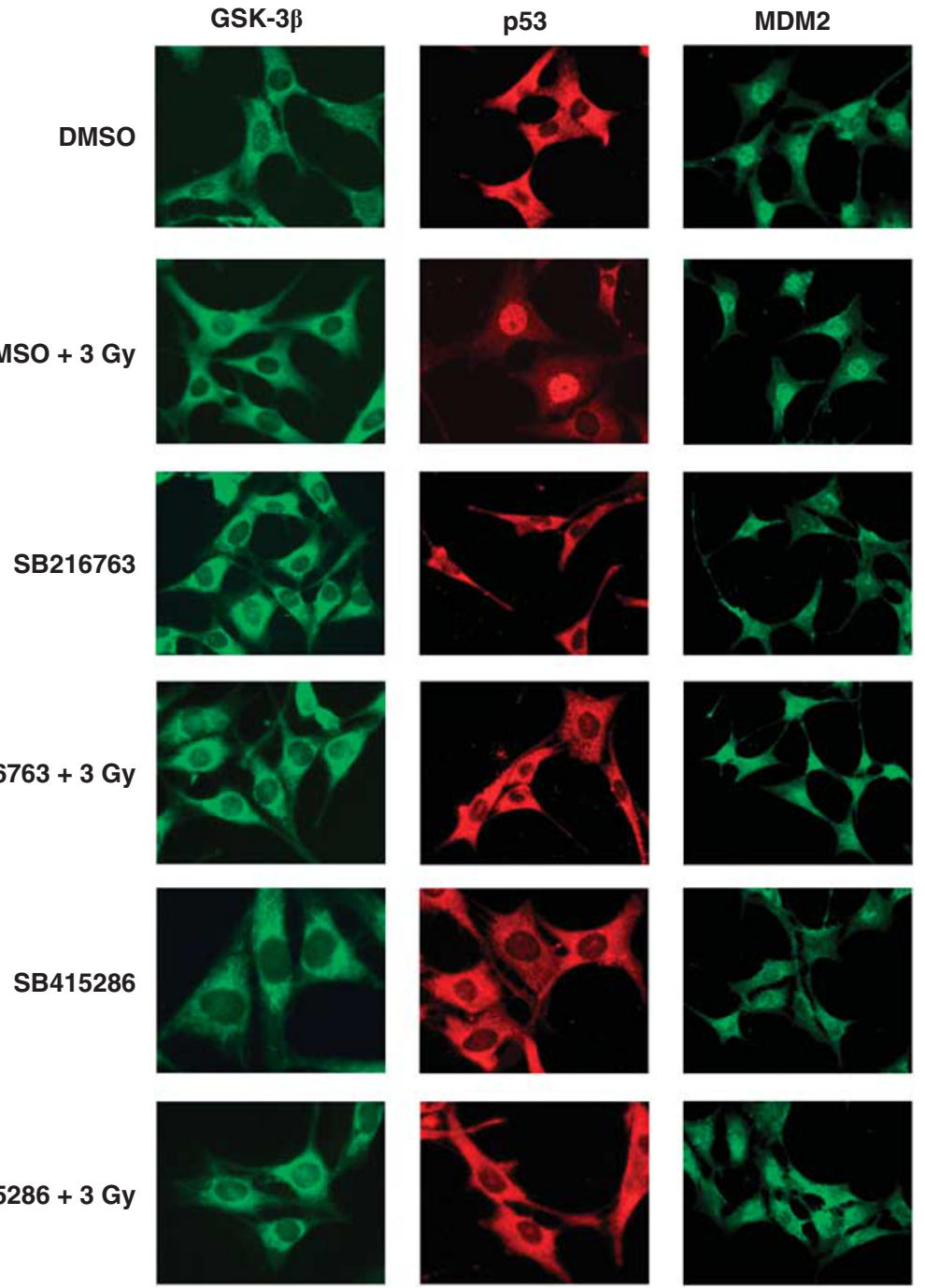

b

SB415286 + 3 Gy

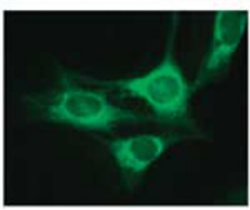

cytoplasmic

nuclear

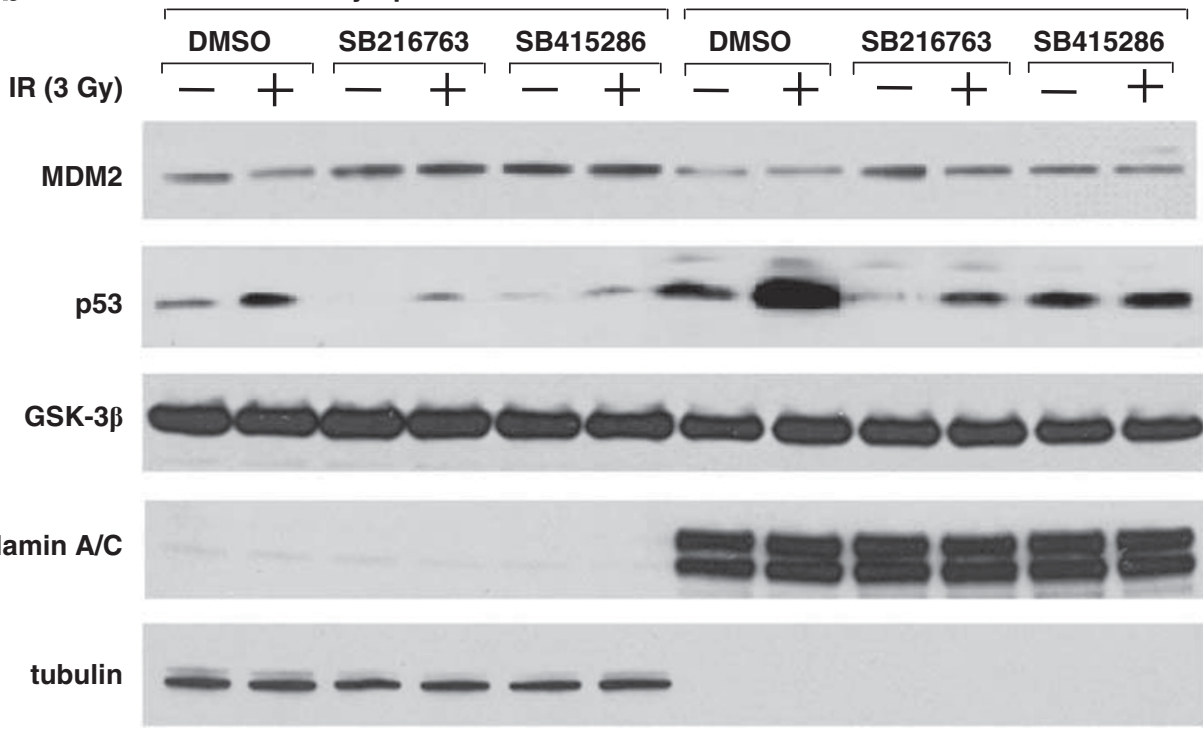


nutlin-3a $(10 \mu \mathrm{M})$ did not offer any protection against radiation induced apoptosis; moreover, the protective effect of GSK-3 $\beta$ knockdown was abrogated by nutlin-3a (Figures 7c and d).

\section{Discussion}

The critical role of p53 in cellular radiosensitivity is widely accepted. ${ }^{33}$ Several factors are involved in the $\mathrm{p} 53$ regulation of downstream cellular effects in response to ionizing

a IP: GSK-3ß

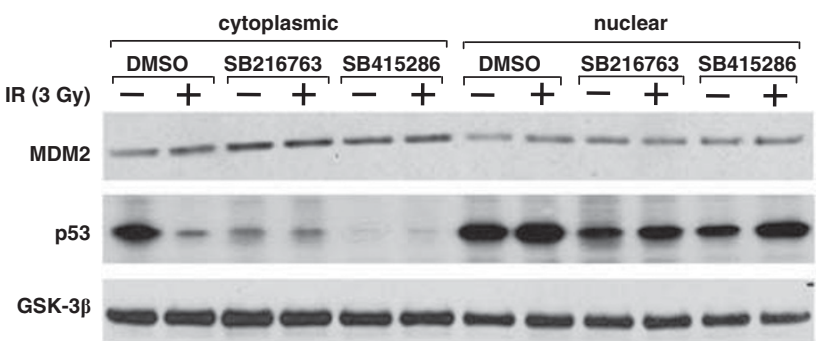

b
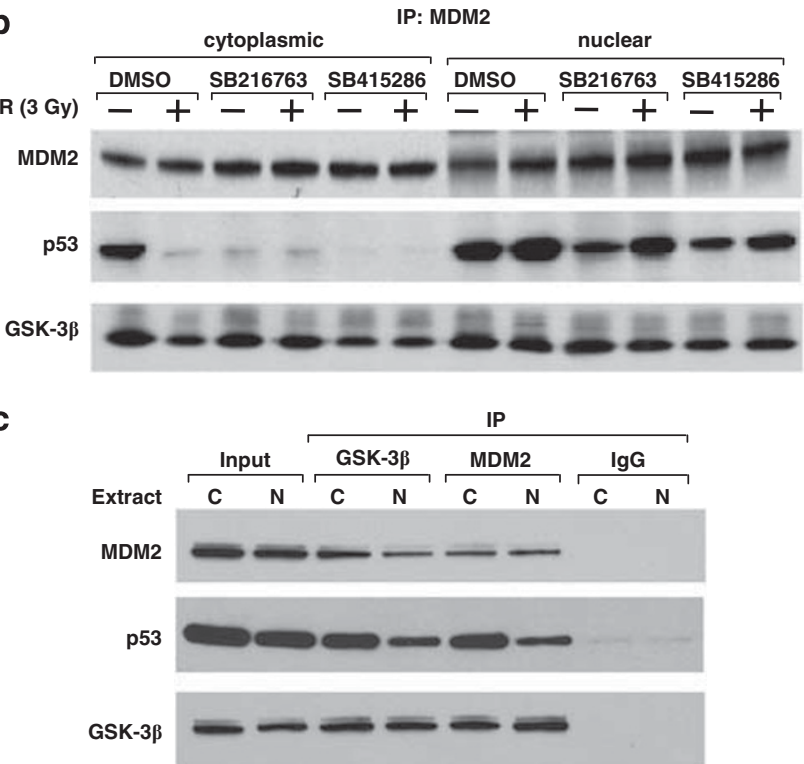

Figure 4 Effect of GSK-3 $\beta$ inhibitors and irradiation on GSK-3 $\beta$, p53 and MDM2 complex formation. HT-22 cells were treated with $10 \mu \mathrm{M} \mathrm{SB} 216763$ or $25 \mu \mathrm{M}$ SB415286 for $16 \mathrm{~h}$, irradiated with $3 \mathrm{~Gy}$ and lysed using NE-PER at $6 \mathrm{~h}$ after irradiation. Cytosolic $(200 \mu \mathrm{g})$ and nuclear $(100 \mu \mathrm{g})$ extracts were immunoprecipitated using anti-GSK-3 $\beta$ (a) or anti-MDM2 (b) antibodies covalently bound to protein A sepharose. The co-immunoprecipitated proteins were immunoblotted using antibodies to p53, GSK-3 $\beta$ and MDM2. (c) Input and negative controls for immunoprecipitations. Cytosolic $(100 \mu \mathrm{g})$ and nuclear $(50 \mu \mathrm{g})$ extracts from untreated HT-22 cells were were used for input controls or were immunoprecipitated using anti-GSK-3 $\beta$, anti-MDM2 or anti-total IgG antibodies covalently bound to protein A sepharose radiation, including tissue specificity. In normal tissues, specifically in hippocampal neurons, therapeutic doses of radiation induce apoptosis that is regulated by $p 53 . .^{11,34,35} \mathrm{On}$ the other hand, GSK-3 $\beta$ is also involved in regulation of the
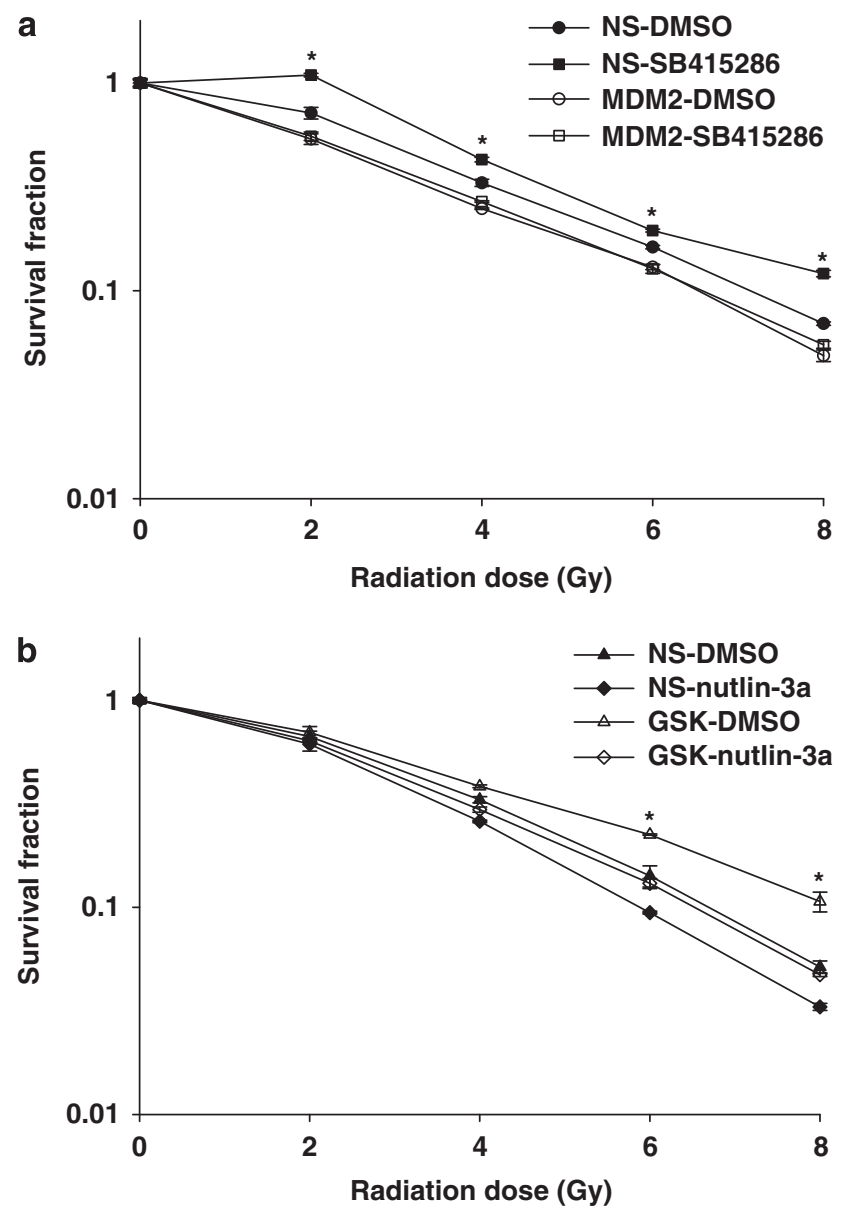

Figure 5 MDM2 mediates the protective effect of GSK-3 $\beta$ inhibitors on survival of irradiated HT-22 neurons. (a) HT-22 neurons were transfected with the nonsilencing (NS) or MDM2-specific shRNA co-expressing GFP in a bicystronic vector (MDM2). The GFP-positive cells were sorted, treated with DMSO $(\bullet, \bigcirc)$ or $25 \mu \mathrm{M}$ of SB415286 $(\square, \square)$ for $16 \mathrm{~h}$, irradiated with $0,2,4,6$ and $8 \mathrm{~Gy}$ and plated for clonogenic survival assay. After 10 days, the colonies were fixed, stained with $1 \%$ methylene blue and counted. Shown are the survival fractions for non-silencing or MDM2-targeting shRNA. S.E.M. are from three experiments; ${ }^{*} P<0.05$ (comparison of NS-SB415286 versus NS-DMSO). (b) HT-22 neurons were infected with viruses generated in HEK293T cells transfected with the NS or GSK-3 $\beta$-specific shRNA (GSK). The cells selected with puromycin were treated with $\operatorname{DMSO}(\boldsymbol{\Lambda}, \triangle)$ or $10 \mu \mathrm{M}$ of nutlin-3a $(\diamond, \diamond)$ for $16 \mathrm{~h}$, irradiated with $0,2,4,6$ and $8 \mathrm{~Gy}$ and plated for clonogenic survival assay. After 10 days, the colonies were fixed, stained with $1 \%$ methylene blue and counted. Shown are the survival fractions for non-silencing or GSK-3 $\beta$-targeting shRNA. S.E.M. are from three experiments; ${ }^{*} P<0.05$ (comparison of GSK-DMSO versus NS-DMSO)

Figure 3 Effect of GSK-3 $\beta$ inhibitors and irradiation on subcellular localization of GSK-3 $\beta$, p53 and MDM2. HT-22 cells were treated with $10 \mu \mathrm{M} \mathrm{SB} 216763$ or $25 \mu \mathrm{M}$ SB415286 for $16 \mathrm{~h}$ and irradiated with $3 \mathrm{~Gy}$. (a) At $6 \mathrm{~h}$ after irradiation, cells were fixed and stained with anti-GSK-3 $\beta$, anti-p53 and anti-MDM2 antibody followed by secondary Alexa 568-conjugated anti-rabbit antibody (Molecular Probes) for GSK-3 $\beta$ and MDM2 and Alexa 488-conjugated anti-mouse antibody (Molecular Probes) for p53. Shown are the representative micrographs. (b) At $6 \mathrm{~h}$ after irradiation, cells were lysed using NE-PER, and $40 \mu \mathrm{g}$ of cytosolic or nuclear extracts were immunoblotted using antibodies to MDM2, p53 and GSK-3 $\beta$ to analyze levels of expression of these proteins. Tubulin and lamin A/C were used to evaluate the purity and protein loading of nuclear and cytoplasmic fraction in each lane 

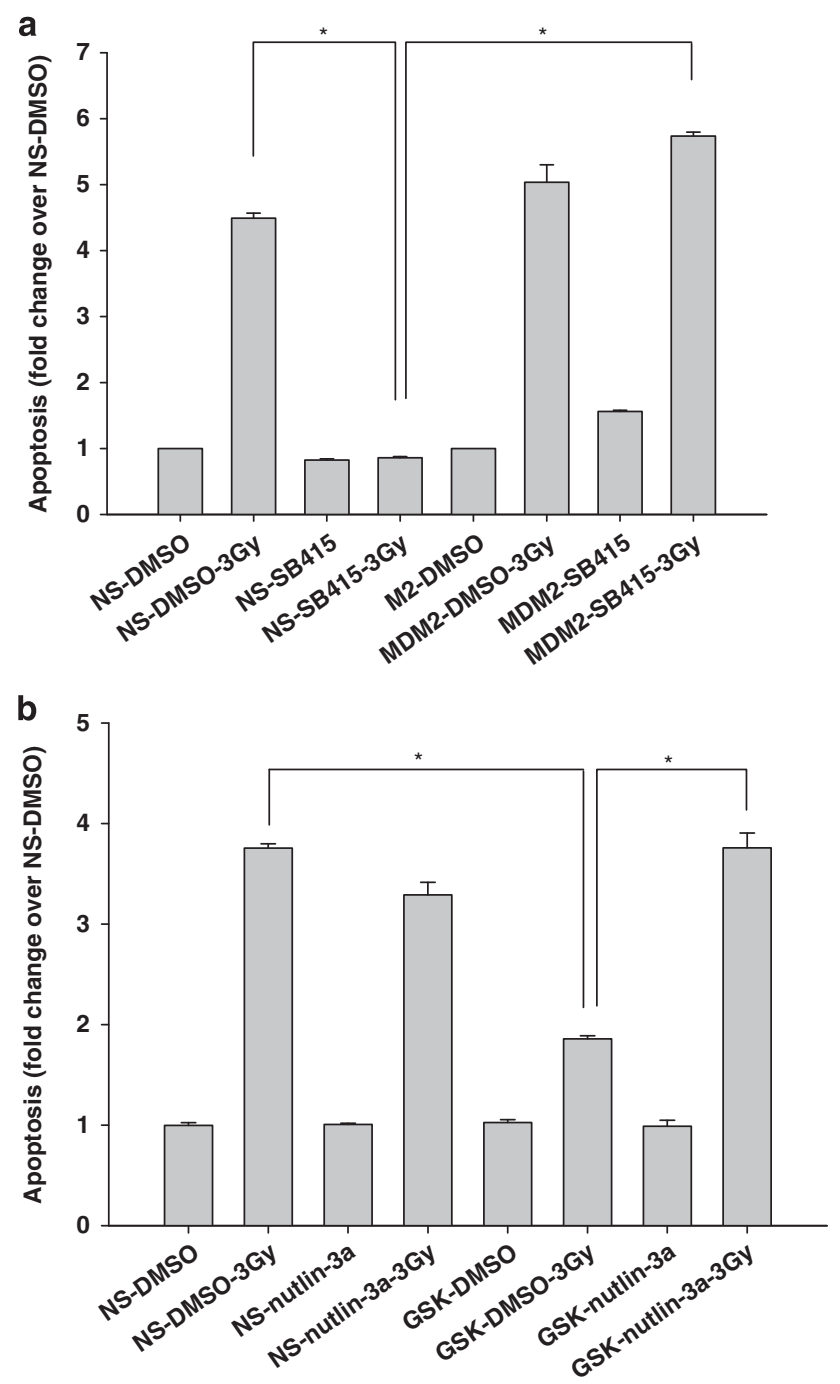

Figure 6 MDM2 mediates the protective effect of GSK-3 $\beta$ inhibitors from radiation-induced apoptosis in HT-22 neurons (annexin V-APC/propidium iodide staining). (a) HT-22 neurons were transiently transfected with the non-silencing or MDM2-specific shRNA co-expressing GFP in a bicystronic vector. The GFP-positive cells were sorted, treated with DMSO or $25 \mu \mathrm{M}$ of SB415286 for $16 \mathrm{~h}$ and irradiated with 3 Gy. At $24 \mathrm{~h}$ post irradiation, cells were stained with annexin V-APC/propidium iodide and analyzed by flow cytometry. Shown is a bar graph of the average percent of apoptotic cells versus total cell number for each treatment with S.E.M. from three experiments; ${ }^{*} P<0.05$. (b) HT-22 neurons were infected with viruses generated in HEK 293T cells transfected with the non-silencing or GSK-3 $\beta$-specific shRNA. The cells selected with puromycin were treated with DMSO or $10 \mu \mathrm{M}$ of nutlin-3a for $24 \mathrm{~h}$ and irradiated with $3 \mathrm{~Gy}$. At $24 \mathrm{~h}$ post irradiation, cells were stained with annexin VAPC/propidium iodide and analyzed by flow cytometry. Shown is a bar graph of the average percentage of apoptotic cells versus total cell number for each treatment with S.E.M. from three experiments; ${ }^{*} P<0.05$ survival of damaged hippocampal neurons, and inhibitors of GSK-3 $\beta$ exhibit a radioprotective effect in these cells. ${ }^{5,11,36,37}$ In addition, GSK-3 $\beta$ was shown to regulate p53 activity by interacting with and phosphorylating p53 and p53-specific E3 ubiquitin ligase MDM2. ${ }^{23,27,32,38}$ We speculate that the mechanisms of radioprotection by GSK-3 $\beta$ inhibitors in hippocampal-derived neurons involve regulation of MDM2dependent p53 accumulation and subcellular localization of GSK-3 $\beta$, MDM2 and p53 that closely correlates with their activity and functions.

At $6 \mathrm{~h}$ after exposure of HT-22 hippocampal-derived neurons to radiation ( $3 \mathrm{~Gy}$ ), we observed considerably elevated phosphorylation of p53 ${ }^{\text {Ser18 }}$, p53 protein stabilization and increased nuclear localization, whereas MDM2 changes were minimal (Figures 1 and 3). This classical p53 response to a cytotoxic agent suggests that radiation-induced apoptosis in HT-22 neurons is p53 dependent. The small molecule inhibitors of GSK-3 $\beta$ blocked radiation-induced effects on p53 leading to the prevention of radiation-induced apoptosis and increased survival of HT-22 neurons. The role of attenuated p53 function in the prosurvival effects of the GSK-3 $\beta$ inhibitors have been previously reported. ${ }^{11,28,39,40}$ However, the specific molecular mechanisms of this effect are yet to be defined.

GSK-3 $\beta$ inhibition also resulted in the accumulation of MDM2. This suggests that presence of sufficient amount of active GSK-3 $\beta$ is essential for MDM2 functions. Inhibition of GSK-3 $\beta$ activity (Figure 1 ) or knockdown of GSK-3 $\beta$ (Figure $2 b$ ) leads to upregulation of MDM2 and degradation of p53, which could not be significantly altered by addition of inhibitors of MDM2-p53 interaction, nutlin-3a or RITA (Figure 2b). This particular observation requires further investigation. As we did not performed time course study of this effect, there could merely reflect an attenuation in p53 accumulation followed by addition of nutlin-3a or RITA. However, we speculate that possible mechanisms of this phenomenon include complex formation between MDM2, GSK-3 $\beta$ and $\mathrm{p} 53$ that is facilitated by active GSK-3 $\beta$. Once GSK-3 $\beta$ inhibited or knocked down, MDM2 is accumulated. MDM2 accumulation could change binding affinity of small molecule inhibitors of MDM2-p53 interaction, such as nutlin$3 a$, in favor to MDMX or other unidentified target(s). ${ }^{41}$

Interestingly, we do not observe MDM2 induction in the presence of inhibitors of MDM2-p53 interaction RITA or nutlin-3a without GSK-3 $\beta$ inhibition (Figure $2 b$ ). In the cells with the wild-type functional p53 and MDM2, such as HT-22 neurons, the biological variability and temporal relationships between stimulated p53 transcriptional activity and increased protein levels of its downstream targets (such as MDM2) are

Figure 7 MDM2 mediates the protective effect of GSK-3 $\beta$ inhibitors from radiation-induced apoptosis in HT-22 neurons (morphological assessment with DAPI staining). (a and b) HT-22 neurons were transiently transfected with the non-silencing or MDM2-specific shRNA co-expressing GFP in a bicystronic vector. The GFP-positive cells were sorted, treated with DMSO or $25 \mu \mathrm{M}$ of SB415286 for $16 \mathrm{~h}$ and irradiated with $3 \mathrm{~Gy}$. At $24 \mathrm{~h}$ post irradiation, cells were fixed and stained with DAPI, and apoptotic cells indicated by arrows were counted in multiple randomly selected fields. Shown are representative micrographs (a) and a bar graph of the average percentage of apoptotic cells versus total cell number for each treatment with S.E.M. from three experiments; ${ }^{*} P<0.05$ (b). (c and d) HT-22 neurons were infected with viruses generated in HEK $293 T$ cells transfected with the non-silencing or GSK-3 $\beta$-specific shRNA. The cells selected with puromycin were treated with DMSO or $10 \mu \mathrm{M}$ of nutlin-3a for $24 \mathrm{~h}$ and irradiated with 3 Gy. At $24 \mathrm{~h}$ post irradiation, cells were fixed and stained with DAPI, and apoptotic cells indicated by arrows were counted along with total cell number per HPF (five to seven randomly selected HPF were counted). Shown are representative micrographs (c) and a bar graph of average percent of apoptotic cells versus total cell number for each treatment with S.E.M. from three experiments; ${ }^{*} P<0.05$ (d) 
a
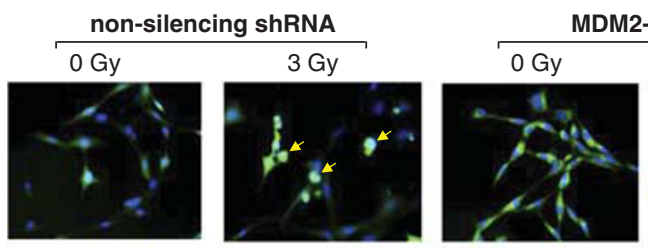

MDM2-shRNA
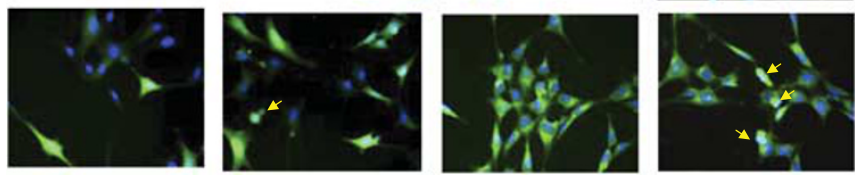

b

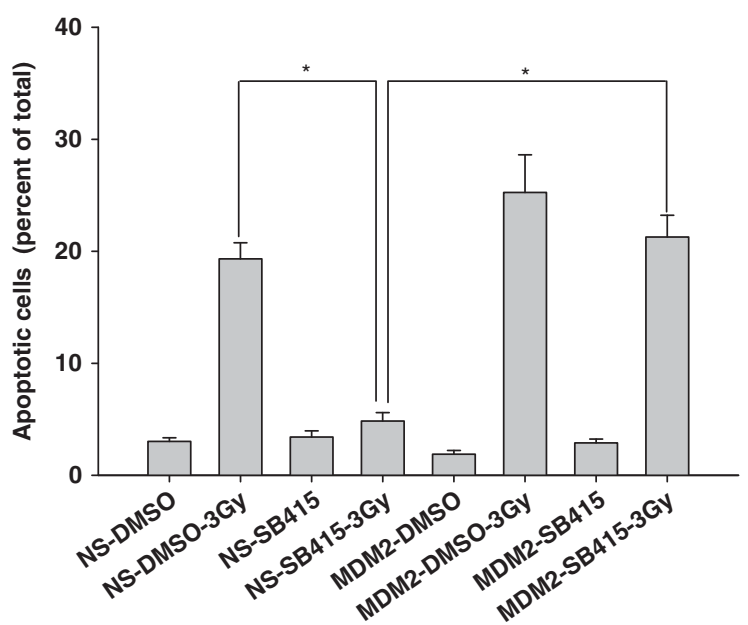

C

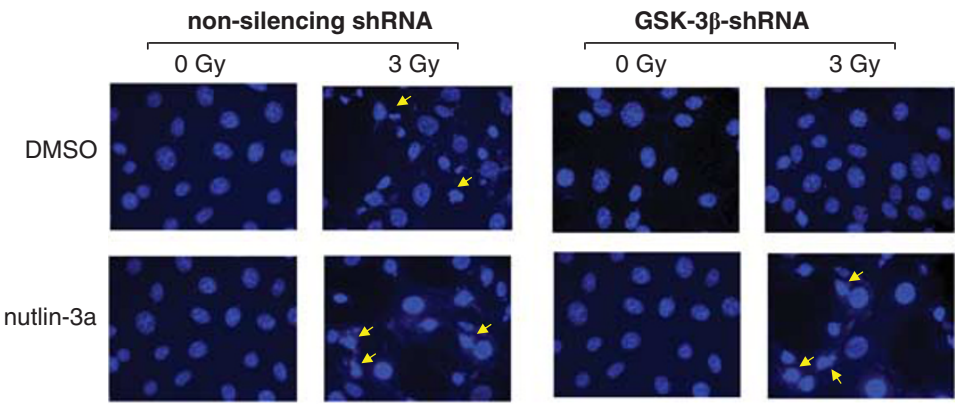

d

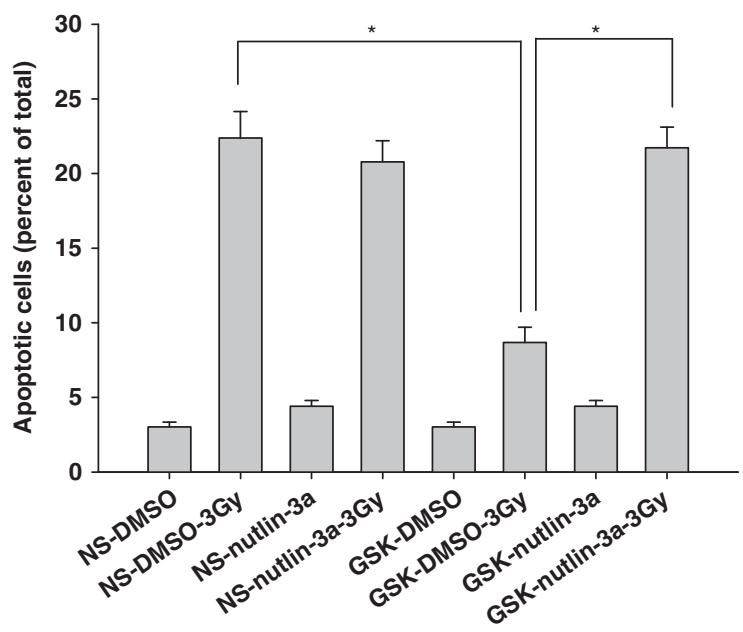


a

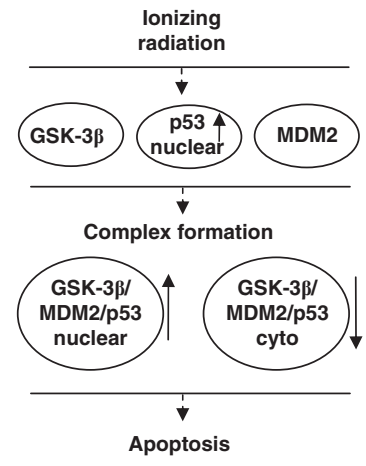

b

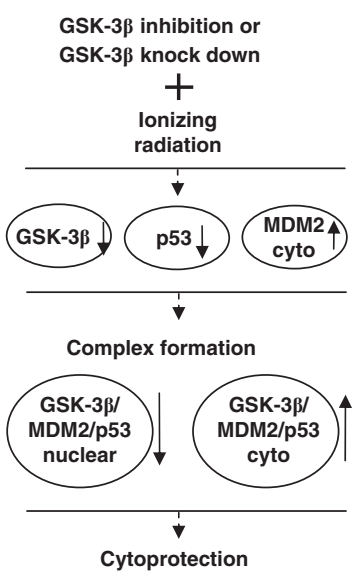

C MDM2 knock down or MDM2/p53 binding inhibition $+$

GSK-3 $\beta$ inhibition or GSK-3 $\beta$ knock down $+$ lonizing radiation

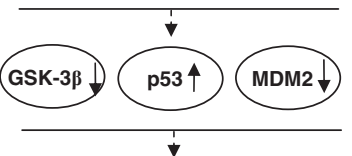

Complex formation

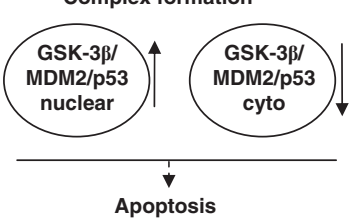

Figure 8 The proposed interaction between MDM2, GSK-3 $\beta$ and p53 in subcellular compartments and resulting cellular responses. (a) Upon irradiation of HT-22 neurons, p53 stabilizes and accumulates in nucleus that triggers increased GSK-3 $\beta /$ p53/MDM2 binding and results in apoptosis. (b) GSK-3 $\beta$ inhibition causes cytoplasmic MDM2 accumulation followed by MDM2-dependent p53 degradation that leads to cellular radioprotection. (c) Additional MDM2 knock down or inhibition of MDM2-p53 interaction reverses radioprotective effect of GSK-3 $\beta$ inhibition

the key determinants of p53-dependent MDM2 accumulation. In the majority of the experiments, we do not observe increased levels of MDM2 in irradiated HT-22 neurons at the same time as we detect p53 accumulation; usually it requires additional time. Similar phenomenon is observed for the small molecule inhibitors of MDM2-p53 interaction. This is supported by number of publications, specifically for nutlin3a. ${ }^{42,43}$ After treatment with nutlin-3a, p53 levels go up first; after some time, the increases in levels of its downstream targets (such as MDM2) are observed. We believe that our data (Figure $2 b$ ) correspond to such time point after treatment with nutlin-3a or RITA.

Although the exact mechanism of how GSK-3 $\beta$ inhibitors lead to upregulation of MDM2 is yet to be discovered, there could be two major possibilities. It was shown that GSK-3 $\beta$ phosphorylates MDM2; ${ }^{32}$ this phosphorylation could potentially interfere with MDM2 autoubiquitination. ${ }^{44}$ The other way to inhibit MDM2 autoubiquitination involves protein-protein interactions. ${ }^{44}$ In this study, we hypothesize that complex formation between MDM2, GSK-3 $\beta$ and p53 is responsible for MDM2 upregulation. Most important, in addition to abrogation of radiation-induced p53 stabilization and upregulation of MDM2, GSK-3 $\beta$ inhibition leads to decreased nuclear levels of MDM2 compared with cytoplasm and decreased nuclear levels of p53 compared with treatment with radiation alone. These data strongly support the idea that radioprotective effect of GSK-3 $\beta$ inhibition in HT-22 neurons engages GSK$3 \beta$-dependent regulation of MDM2, which, in turn, regulates p53 functions and p53-dependent cellular responses.

To further confirm this idea, we undertook comprehensive inhibitory approach: we genetically knocked down either MDM2 or GSK-3 $\beta$ with specific shRNA, or inhibited either GSK-3 $\beta$ or MDM2-p53 interaction with small molecule inhibitors. Summarizing these experiments, we confirmed two important molecular events occurring in hippocampal neurons: (1) presence of active GSK-3 $\beta$ is required for radiation-induced p53 accumulation; (2) prevention of radia- tion-induced $\mathrm{p} 53$ accumulation by GSK-3 $\beta$ inhibition involves MDM2 upregulation. Therefore, we could conclude that radiation responses in hippocampal neurons involve, at least, GSK-3 $\beta$, MDM2 and $\mathrm{p} 53$, as GSK-3 $\beta$ inhibition prevented radiation-induced p53 accumulation through MDM2 upregulation and abolished radiation-induced apoptosis. Direct involvement of GSK-3 $\beta$ in radiation effects in hippocampal neurons is yet to be determined, as we did not observe a significant radiation-induced change in GSK-3 $\beta$ phosphorylation or subcellular localization. ${ }^{5,11}$ These observations are in disagreement with the results published by Kulikov et al. ${ }^{32}$ that demonstrated significant radiation-induced inhibition of GSK-3 $\beta$. One of the possible explanations for the differences could be the cell type specificity: in our study, we used hippocampal-derived neurons, whereas Kulikov et al. used cancer cell lines. We have reported previously dramatic differences in the radiation-induced cell survival of HT-22 hippocampal-derived neurons and brain tumor cell lines. ${ }^{5,11}$ We also demonstrated that radioprotective effect of GSK-3 $\beta$ inhibition is specific for hippocampal-derived neurons as compared with brain tumor cell lines. ${ }^{5,11}$ There is a possibility that GSK-3 $\beta$ involvement in the radiation responses is indirect, through interaction with p53 after its translocation to the nucleus. This could trigger p53 downregulation of several survival-promoting transcription factors that are known to be phosphorylated by GSK-3 $\beta$ in the nucleus, the inhibition of which would promote p53-dependent apoptosis. ${ }^{19}$

We suggest that the radioprotective effects of GSK-3 $\beta$ inhibition also involve, at least, three proteins, GSK-3 $\beta$, p53 and MDM2, and the role of MDM2 in these effects is essential. In our co-immunoprecipitation study, we demonstrated that GSK-3 $\beta$, p53 and MDM2 bind to each other in cytosolic and nuclear fractions of HT-22 cells (Figure 4). Depending on treatment, there are preferences in three-protein complex formation in subcellular compartments. The proposed interaction between MDM2, GSK-3 $\beta$ and p53 and resulting cellular responses are described in Figure 8. On irradiation of HT-22 
neurons, p53 stabilizes and accumulates in the nucleus that triggers increased GSK-3 $\beta /$ p53/MDM2 binding and results in apoptosis (Figure 8a). GSK-3 $\beta$ inhibition causes cytoplasmic MDM2 accumulation followed by MDM2-dependent p53 degradation that leads to cellular radioprotection (Figure 8b). Additional MDM2 knockdown or inhibition of MDM2-p53 interaction reverses radioprotective effect of GSK-3 $\beta$ inhibition (Figure 8c).

In summary, these findings uncover mechanisms of radiation-induced cytotoxicity and radioprotection in HT-22 hippocampal-derived neurons involving GSK-3 $\beta$, p53 and MDM2. The revelation that the neuroprotective effect of GSK$3 \beta$ inhibitors includes modulation of p53 function through a MDM2-dependent mechanism presents opportunities for therapeutic intervention. Specifically, GSK-3 $\beta$ inhibitors could be developed for protection of the brain and thereby prevent radiation-induced neurocognitive deficiencies observed in cancer survivors.

\section{Materials and Methods}

Cell cultures and treatment. HT-22 cells, glutamate-sensitive clone derived from immortalized mouse hippocampal cell line ${ }^{45}$ were obtained from David Schubert (The Salk Institute, La Jolla, CA, USA) and maintained in Dulbecco's modified Eagle's medium with 10\% fetal bovine serum (FBS) and 1\% penicillin/ streptomycin (Life Technologies, Gaithersburg, MD, USA). Cells were grown in a $5 \% \mathrm{CO}_{2}$ incubator at $37^{\circ} \mathrm{C}$. For experiments with GSK-3 $\beta$ inhibitors, cells were treated with $10 \mu \mathrm{M}$ SB216763 or $25 \mu \mathrm{M} \mathrm{SB} 415286$ for $16 \mathrm{~h}$ before irradiation. ${ }^{11}$ For experiments with MDM2 inhibitors, cells were treated with $1 \mu \mathrm{M}$ RITA or $10 \mu \mathrm{M}$ nutlin-3a for $24 \mathrm{~h}$ before irradiation. For the radiation of cells, Therapax DXT 300 X-ray machine (Pantak Inc., East Haven, CT, USA) delivering 2.04 Gy/min at $80 \mathrm{kVP}$ was used.

Chemicals. SB415286 (3-((3-chloro-4-hydroxyphenyl)amino)-4-(2-nitrophenyl)1H-pyrrole-2,5-dione), SB216763 (3-(2,4-dichlorophenyl)-4-(1-methyl-1H-indol-3-yl)$1 \mathrm{H}$-pyrrole-2,5-dione) and RITA (5,5'-92,5-furandiyl) bis-2-thiophenemethanol) were purchased from Tocris biosciences (Ellisville, MO, USA). Nutlin-3a (( \pm$)-4$ (4,5-Bis(4-chlorophenyl)-2-(2-isopropoxy-4-methoxy-phenyl)-4,5-dihydro-imidazole-1carbonyl)-piperazin-2-one) was purchased from Sigma-Aldrich (St. Louis, MO, USA). Nutlin-3a binds to MDM2 and alters the binding of MDM2 to other proteins.

Silencing of MDM2 with shRNA. HT-22 cells were transiently transfected using the pGIPZ lentiviral plasmid vector (Open Biosystems, Huntsville, AL, USA). This bicistronic vector allows estimation of the level of transfection by expressing of shRNA of interest in the first cistron, while keeping a high level of expression from second cistron encoding green fluorescent protein (GFP). The vector contained either non-silencing scrambled shRNA or shRNA specific for mouse MDM2 (5'-TCT TGTTGACAGTGAGCGCGGATTGAAGCGGAGATCTAAATAGTGAAGCCACAG ATGTATTTAGATCTCCGCTTCAATCCATGCCTACTGCCTCGGA-3'). HT-22 cells were seeded at $40-50 \%$ confluency and transfected the following day with $5-10 \mu \mathrm{g}$ of expression vectors with Lipofectamine 2000 reagent (Invitrogen Corporation, Carlsbad, CA, USA) according to the manufacturer's protocol. Cells were examined microscopically at 24 and $48 \mathrm{~h}$ post transfection for TurboGFP expression to estimate the level of transfection. The cells were trypsinized, resuspended in phosphate-buffered saline (PBS) and sorted for GFP-positive cells using the BD FACS Aria cell sorter (BD Biosciences, San Jose, CA, USA). The GFP-positive cells were further tested for MDM2 expression by immunoblotting and then used for clonogenic survival assays, apoptosis assays and immunoblot analyses.

Silencing of GSK-3 $\beta$ with shRNA. To identify shRNA sequences that could knockdown GSK-3 $\beta$ in HT-22 hippocampal neuronal cells, we screened five MISSION shRNA clones NM_019827.2-1527s1c1 (Sigma, St. Louis, MO, USA) targeted against the mouse GSK-3 $\beta$ sequence. The effect of the shRNA clones on GSK-3 $\beta$ protein levels in HT-22 cells was assayed by immunoblotting using antiGSK-3 $\beta$ antibody (Cell Signaling Technologies, Danvers, MA, USA). The clone with the best results for knockdown of GSK-3 $\beta$ was selected (5'-CCGGCATGAAA GTTAGCAGAGATAACTCGAGTTATCTCTGCTAACTTTCATGTTTTT-3'), and a clone that gave no significant change in GSK-3 $\beta$ expression ( $5^{\prime}$-CCGGCGAGAA GAAAGATGAGGTCTACTCGAGTAGACCTCATCTTTCTTCTCGTTTTT-3') was used as a control. MISSION shRNA clones together with packaging and envelope plasmids PUMVC and PCMV-VSV-G (provided by Sheila Stewart, Washington University) were transfected into HEK293T packaging cells using Fugene (Promega, Madison, WI, USA). At $48 \mathrm{~h}$ post transfection, virus-containing media was used to infect HT-22 cells. GFP was used to monitor the efficiency of HEK293T transfection and HT-22 infection. After selection with puromycin $(2 \mu \mathrm{g} / \mathrm{ml})$ for $36-48 \mathrm{~h}$, cells were tested for GSK-3 $\beta$ expression by immunoblotting and then used for clonogenic survival assays, apoptosis assays and immunoblot analyses.

Clonogenic survival assay. Colony-forming assay was performed as previously described. ${ }^{5}$ Briefly, counted cells were plated to enable normalization for plating efficiencies. Cells were allowed to attach for $5 \mathrm{~h}$ and then irradiated with 0,2 , 4,6 or 8 Gy. After $7-10$ day incubation, plates were fixed with $70 \% \mathrm{EtOH}$ and stained with $1 \%$ methylene blue. Colonies consisting of $>50$ cells were counted using microscopy. The survival fractions were calculated as: (number of colonies/ number of cells plated)/(number of colonies for corresponding control/number of cells plated).

Apoptosis assays. Apoptosis was determined by annexin V-APC/propidium iodide staining using Apoptosis Detection Kit (BD PharMingen, San Diego, CA, USA). Briefly, aliquots of $10^{5}$ treated cells were incubated with annexin V/propidium iodide for 15 min at room temperature and analyzed by flow cytometry using a twocolor FACS analysis (BD LSR II, BD Biosciences). For each treatment, the average fold-increase of apoptotic cells over control ( \pm S.E.M.) was calculated.

Apoptosis was also determined by DAPI staining. The cells were grown on slides, treated, washed with PBS, fixed in $4 \%$ paraformaldehyde for $10 \mathrm{~min}$ and stained with $5 \mu \mathrm{g} / \mathrm{ml}$ of DAPI at room temperature for $10 \mathrm{~min}$. The nuclear morphology was observed using fluorescent microscope equipped with digital camera. Condensed or fragmented nuclei were scored as apoptotic; average percentage of apoptotic cells ( \pm S.E.M.) was calculated in five to seven randomly selected HPF.

Immunoblot analysis. Cells were lysed using M-PER (Pierce, Rockford, IL, USA). Nuclear and cytoplasmic cell extracts were prepared using NE-PER (Pierce). Protein concentration was quantified using bicinchoninic acid reagent (Pierce). Protein extracts $(40 \mu \mathrm{g})$ were subjected to western immunoblot analysis using antibodies for the detection of $\beta$-catenin, p53, phospho-p53 $3^{\operatorname{ser} 18}$, GSK-3 $\beta$ (all from Cell Signaling Technologies) and MDM2 (Santa Cruz Biotechnology, Inc., Santa Cruz, CA, USA); antibody to actin (Sigma) was used to evaluate protein loading in each lane. Immunoblots were developed using the western Lightning Chemiluminescence Plus detection system (PerkinElmer, Wellesley, MA, USA) according to the manufacturer's protocol. Relative protein levels were determined by densitometry and normalized to actin and to control (cells treated with DMSO).

Immunofluorescence staining. HT-22 cells were plated on glass cover slips in six-well plates. After treatment, cells were fixed with $4 \%$ paraformaldehyde for $15 \mathrm{~min}$ at $37^{\circ} \mathrm{C}$. The cells were permeabilized using $0.1 \%$ Triton X-100 (Fisher Scientific, Pittsburgh, PA, USA) for $10 \mathrm{~min}$, blocked with $10 \%$ FBS in PBS for $1 \mathrm{~h}$ at room temperature and incubated with primary antibodies for either GSK-3 $\beta$, p53 (Cell Signaling Technology), or MDM2 (Santa Cruz Biotechnology) in 10\% FBS in PBS overnight at $4^{\circ} \mathrm{C}$. After washing with $1 \%$ FBS in PBS for 20 min, cells were incubated with the secondary Alexa 488-conjugated antibody (Molecular Probes, Invitrogen; anti-mouse for p53 or anti-rabbit for GSK-3 $\beta$ and MDM2, respectively) for $30 \mathrm{~min}$ at room temperature. The cells were washed with PBS, mounted using Aqua-Mount (Fisher Scientific), visualized using Leica microscope (Leica Microsystems Inc., Buffalo Grove, IL, USA) and digital images were captured using the IP Lab software (BD Biosciences).

Co-immunoprecipitation analysis. The anti-GSK-3 $\beta$ and anti-MDM2 antibodies $(200 \mu \mathrm{g})$ were covalently coupled to protein G-Sepharose $(1 \mathrm{ml}$ of $50 \%$ slurry) using the dimethyl pimelimidate method as previously described. ${ }^{46}$ Cell lysates (100-200 $\mu \mathrm{g}$ total protein) were incubated with coupled antibody $(40 \mu \mathrm{l}$ of $50 \%$ slurry) at $4{ }^{\circ} \mathrm{C}$ overnight. The co-immunoprecipitated proteins were eluted by adding $30 \mu \mathrm{l}$ of $2 \times$ Laemmli sample buffer, boiled with $5 \%(\mathrm{v} / \mathrm{v})$ $\beta$-mercaptoethanol, separated on SDS-PAGE and analyzed by immunoblotting using antibodies to detect GSK-3 $\beta$, p53 and MDM2. 
Statistical analyses. The mean and S.E.M. of each treatment group were calculated for all experiments. The number of samples is indicated in the description of each experiment. Statistical analysis was performed using Kruskal-Wallis one-way analysis of variance. All pair wise comparison procedures including calculation of $P$-value were performed by use of Student-Newman-Keuls method. A $P$-value of $<0.05$ was considered significant.

\section{Conflict of Interest}

The authors declare no conflict of interest.

Acknowledgements. This work was supported by Public Health Service grants R01-CA140220; R01-CA112385; R01-CA125757, R01-CA093240, from the National Cancer Institute, and support from the Department of Radiation Oncology at Washington University.

1. Deweer B, Pillon B, Pochon JB, Dubois B. Is the HM story only a 'remote memory'? Some facts about hippocampus and memory in humans. Behav Brain Res 2001; 127: 209-224.

2. Monje ML, Mizumatsu S, Fike JR, Palmer TD. Irradiation induces neural precursor-cell dysfunction. Nat Med 2002; 8: 955-962.

3. Nagai $R$, Tsunoda $S$, Hori $Y$, Asada $H$. Selective vulnerability to radiation in the hippocampal dentate granule cells. Surg Neurol 2000; 53: 503-506; discussion 506-507.

4. Peissner W, Kocher M, Treuer H, Gillardon F. Ionizing radiation-induced apoptosis of proliferating stem cells in the dentate gyrus of the adult rat hippocampus. Brain Res $\mathrm{Mol}$ Brain Res 1999; 71: 61-68.

5. Yazlovitskaya EM, Edwards E, Thotala D, Fu A, Osusky KL, Whetsell Jr WO et al. Lithium treatment prevents neurocognitive deficit resulting from cranial irradiation. Cancer Res 2006; 66: 11179-11186.

6. Ferrer I, Serrano T, Alcantara S, Tortosa A, Graus F. X-ray-induced cell death in the developing hippocampal complex involves neurons and requires protein synthesis. J Neuropathol Exp Neurol 1993; 52: 370-378.

7. Mizumatsu S, Monje ML, Morhardt DR, Rola R, Palmer TD, Fike JR. Extreme sensitivity of adult neurogenesis to low doses of X-irradiation. Cancer Res 2003; 63: 4021-4027.

8. Madsen TM, Kristjansen PE, Bolwig TG, Wortwein G. Arrested neuronal proliferation and impaired hippocampal function following fractionated brain irradiation in the adult rat. Neuroscience 2003; 119: 635-642.

9. Rola R, Raber J, Rizk A, Otsuka S, VandenBerg SR, Morhardt DR et al. Radiation-induced impairment of hippocampal neurogenesis is associated with cognitive deficits in young mice. Exp Neurol 2004; 188: 316-330.

10. Raber J, Rola R, LeFevour A, Morhardt D, Curley J, Mizumatsu S et al. Radiation-induced cognitive impairments are associated with changes in indicators of hippocampal neurogenesis. Radiat Res 2004; 162: 39-47.

11. Thotala DK, Hallahan DE, Yazlovitskaya EM. Inhibition of glycogen synthase kinase 3 beta attenuates neurocognitive dysfunction resulting from cranial irradiation. Cancer Res 2008; 68: 5859-5868.

12. Embi N, Rylatt DB, Cohen P. Glycogen synthase kinase-3 from rabbit skeletal muscle. Separation from cyclic-AMP-dependent protein kinase and phosphorylase kinase. Eur J Biochem 1980; 107: 519-527.

13. Doble BW, Woodgett JR. GSK-3: tricks of the trade for a multi-tasking kinase. J Cell Sci 2003; 116: 1175-1186.

14. Pap M, Cooper GM. Role of translation initiation factor $2 B$ in control of cell survival by the phosphatidylinositol 3-kinase/Akt/glycogen synthase kinase 3beta signaling pathway. Mol Cell Biol 2002; 22: 578-586.

15. Sanchez JF, Sniderhan LF, Williamson AL, Fan S, Chakraborty-Sett S, Maggirwar SB. Glycogen synthase kinase 3beta-mediated apoptosis of primary cortical astrocytes involves inhibition of nuclear factor kappaB signaling. Mol Cell Biol 2003; 23: 4649-4662.

16. Jope RS, Johnson GV. The glamour and gloom of glycogen synthase kinase-3. Trends Biochem Sci 2004; 29: 95-102.

17. Beurel E, Jope RS. The paradoxical pro- and anti-apoptotic actions of GSK3 in the intrinsic and extrinsic apoptosis signaling pathways. Prog Neurobiol 2006; 79: 173-189.

18. Bijur GN, De Sarno P, Jope RS. Glycogen synthase kinase-3beta facilitates staurosporineand heat shock-induced apoptosis. Protection by lithium. J Biol Chem 2000; 275: 7583-7590.

19. Grimes CA, Jope RS. The multifaceted roles of glycogen synthase kinase 3 beta in cellular signaling. Prog Neurobiol 2001; 65: 391-426.
20. Forde JE, Dale TC. Glycogen synthase kinase 3: a key regulator of cellular fate. Cell Mol Life Sci 2007; 64: 1930-1944.

21. Bijur GN, Jope RS. Glycogen synthase kinase-3 beta is highly activated in nuclei and mitochondria. Neuroreport 2003; 14: 2415-2419.

22. Ciani L, Salinas PC. WNTs in the vertebrate nervous system: from patterning to neuronal connectivity. Nat Rev Neurosci 2005; 6: 351-362.

23. Watcharasit P, Bijur GN, Zmijewski JW, Song L, Zmijewska A, Chen X et al. Direct, activating interaction between glycogen synthase kinase-3beta and p53 after DNA damage. Proc Natl Acad Sci USA 2002; 99: 7951-7955.

24. Eom TY, Roth KA, Jope RS. Neural precursor cells are protected from apoptosis induced by trophic factor withdrawal or genotoxic stress by inhibitors of glycogen synthase kinase 3 . J Biol Chem 2007; 282: 22856-22864.

25. Oren M. Decision making by p53: life, death and cancer. Cell Death Differ 2003; 10: $431-442$.

26. Kruse JP, Gu W. Modes of p53 regulation. Cell 2009; 137: 609-622.

27. Watcharasit $P$, Bijur GN, Song $L$, Zhu J, Chen X, Jope RS. Glycogen synthase kinase3beta (GSK3beta) binds to and promotes the actions of p53. J Biol Chem 2003; 278: 48872-48879.

28. Beurel E, Kornprobst M, Blivet-Van Eggelpoel MJ, Ruiz-Ruiz C, Cadoret A, Capeau J et al. GSK-3beta inhibition by lithium confers resistance to chemotherapy-induced apoptosis through the repression of CD95 (Fas/APO-1) expression. Exp Cell Res 2004; 300: 354-364.

29. Turenne GA, Price BD. Glycogen synthase kinase 3 beta phosphorylates serine 33 of $p 53$ and activates p53's transcriptional activity. BMC Cell Biol 2001; 2: 12.

30. Pluquet O, Qu LK, Baltzis D, Koromilas AE. Endoplasmic reticulum stress accelerates p53 degradation by the cooperative actions of $\mathrm{Hdm} 2$ and glycogen synthase kinase 3 beta. $\mathrm{Mol}$ Cell Biol 2005; 25: 9392-9405.

31. Qu L, Huang S, Baltzis D, Rivas-Estilla AM, Pluquet O, Hatzoglou M et al. Endoplasmic reticulum stress induces p53 cytoplasmic localization and prevents p53-dependent apoptosis by a pathway involving glycogen synthase kinase-3beta. Genes Dev 2004; 18: 261-277.

32. Kulikov R, Boehme KA, Blattner C. Glycogen synthase kinase 3-dependent phosphorylation of Mdm2 regulates p53 abundance. Mol Cell Biol 2005; 25: 7170-7180.

33. Lu C, El-Deiry WS. Targeting p53 for enhanced radio- and chemo-sensitivity. Apoptosis 2009; 14: 597-606.

34. Johnson MD, Xiang H, London S, Kinoshita Y, Knudson M, Mayberg M et al. Evidence for involvement of Bax and p53, but not caspases, in radiation-induced cell death of cultured postnatal hippocampal neurons. J Neurosci Res 1998; 54: 721-733.

35. Limoli CL, Giedzinski E, Rola R, Otsuka S, Palmer TD, Fike JR. Radiation response of neural precursor cells: linking cellular sensitivity to cell cycle checkpoints, apoptosis and oxidative stress. Radiat Res 2004; 161: 17-27.

36. Silva R, Mesquita AR, Bessa J, Sousa JC, Sotiropoulos I, Leao P et al. Lithium blocks stress-induced changes in depressive-like behavior and hippocampal cell fate: the role of glycogen-synthase-kinase-3beta. Neuroscience 2008; 152: 656-669.

37. Min YK, Lee JE, Chung KC. Zinc induces cell death in immortalized embryonic hippocampal cells via activation of Akt-GSK-3beta signaling. Exp Cell Res 2007; 313: 312-321.

38. Ghosh JC, Altieri DC. Activation of p53-dependent apoptosis by acute ablation of glycogen synthase kinase-3beta in colorectal cancer cells. Clin Cancer Res 2005; 11: 4580-4588.

39. Lu R, Song L, Jope RS. Lithium attenuates $p 53$ levels in human neuroblastoma SH-SY5Y cells. Neuroreport 1999; 10: 1123-1125.

40. Zmijewski JW, Jope RS. Nuclear accumulation of glycogen synthase kinase-3 during replicative senescence of human fibroblasts. Aging Cell 2004; 3: 309-317.

41. Shangary S, Wang S. Small-molecule inhibitors of the MDM2-p53 protein-protein interaction to reactivate p53 function: a novel approach for cancer therapy. Annu Rev Pharmacol Toxicol 2009; 49: 223-241.

42. van Leeuwen IM, Higgins M, Campbell J, Brown CJ, McCarthy AR, Pirrie L et al. Mechanism-specific signatures for small-molecule p53 activators. Cell Cycle 2011; 10: 1590-1598.

43. Villalonga-Planells R, Coll-Mulet L, Martinez-Soler F, Castano E, Acebes JJ, GimenezBonafe $P$ et al. Activation of $p 53$ by nutlin-3a induces apoptosis and cellular senescence in human glioblastoma multiforme. PLoS One 2011; 6: e18588.

44. Meek DW, Knippschild U. Posttranslational modification of MDM2. Mol Cancer Res 2003; 1: 1017-1026.

45. Morimoto BH, Koshland Jr DE. Induction and expression of long- and short-term neurosecretory potentiation in a neural cell line. Neuron 1990; 5: 875-880.

46. Persons DL, Yazlovitskaya EM, Pelling JC. Effect of extracellular signal-regulated kinase on p53 accumulation in response to cisplatin. J Biol Chem 2000; 275: 35778-35785. 